\title{
Disposal of Shippingport LWBR Spent Nuclear Fuel in Yucca Mountain: Waste Package Internal Criticality Analysis
}

\author{
Horia R. Radulescu, J. Wesley Davis \\ Framatome Cogema Fuels, 1180 Town Center Dr., Las Vegas, Nevada 89144 \\ Leland M. Montierth \\ Idaho National Engineering and Environmental Laboratory, \\ 2525 N. Fremont Ave., Idaho Falls, Idaho 83145
}

\begin{abstract}
The paper presents the disposal criticality analysis for the Shippingport Light Water Breeder Reactor (LWBR) spent nuclear fuel (SNF) being considered for disposal at the potential Yucca Mountain repository. The methodology for disposal criticality analysis ${ }^{1}$ includes the evaluation of the potential configurations - intact through degraded - based on the supporting analyses of the physical and geochemical processes that degrade the fuel over time.
\end{abstract}

\section{INTRODUCTION}

There are more than 250 forms of Department of Energy (DOE)-owned spent nuclear fuel (SNF). Due to the variety of the SNF, the National Spent Nuclear Fuel Program at the Idaho national Engineering and Environmental Laboratory (INEEL) has designated nine representative fuel groups for disposal criticality analyses based on following four characteristics: fuel matrix, composition, primary fissile isotope, and enrichment. Shippingport LWBR SNF is representative of the thorium-uranium $(\mathrm{Th} / \mathrm{U})$ oxide fuel group, because its fuel matrix is a mixture of thorium and highly enriched U-233 oxides. Shippingport LWBR was a 236.6-MW(t) water-cooled breeder reactor based on the U-233/Th-232 fuel cycle. Nuclear design of the LWBR core utilized a seed-blanket concept, with reactivity control provided by core geometry changes (movable fuel) instead of neutron-absorber rods. There are six types of Shippingport LWBR fuel assemblies: one for the seed region, three for the blanket region, and two for the core-reflector region. Because they are the most reactive, only the seed assemblies are considered for this analysis. Demonstration that other fuels in this group are bounded by the Shippingport LWBR fuel analysis remains a future task before these fuel forms will be accepted for disposal.

The Shippingport LWBR core contained about 17,290 fuel rods in 39 fuel assemblies of all types. Currently, there are 27 intact assemblies (of which 8 are seed type), 12 partially derodded assemblies (4 seed), and about 1,000 spent fuel rods (removed from the various types of assemblies for testing) in dry storage.

\section{DESCRIPTION OF THE SHIPPINGPORT LWBR SNF AND CODISPOSAL WASTE PACKAGE}

For codisposal of the Shippingport LWBR fuel with the high-level waste (HLW) glass in the same waste package (WP), the Shippingport LWBR SNF seed assemblies are to be sealed inside standardized 18-inch DOE SNF canisters ${ }^{2}$. One DOE SNF canister is placed in a carbon-steel 
support tube in the center of the waste package's internal support structure (referred to as the basket [Figure 1]). The five HLW canisters are placed inside the waste package's carbon steel basket so they are evenly spaced around the DOE SNF canister. The HLW canisters have a cylindrical stainless steel shell with an outer diameter of approximately $610 \mathrm{~mm}$ (24 in.).

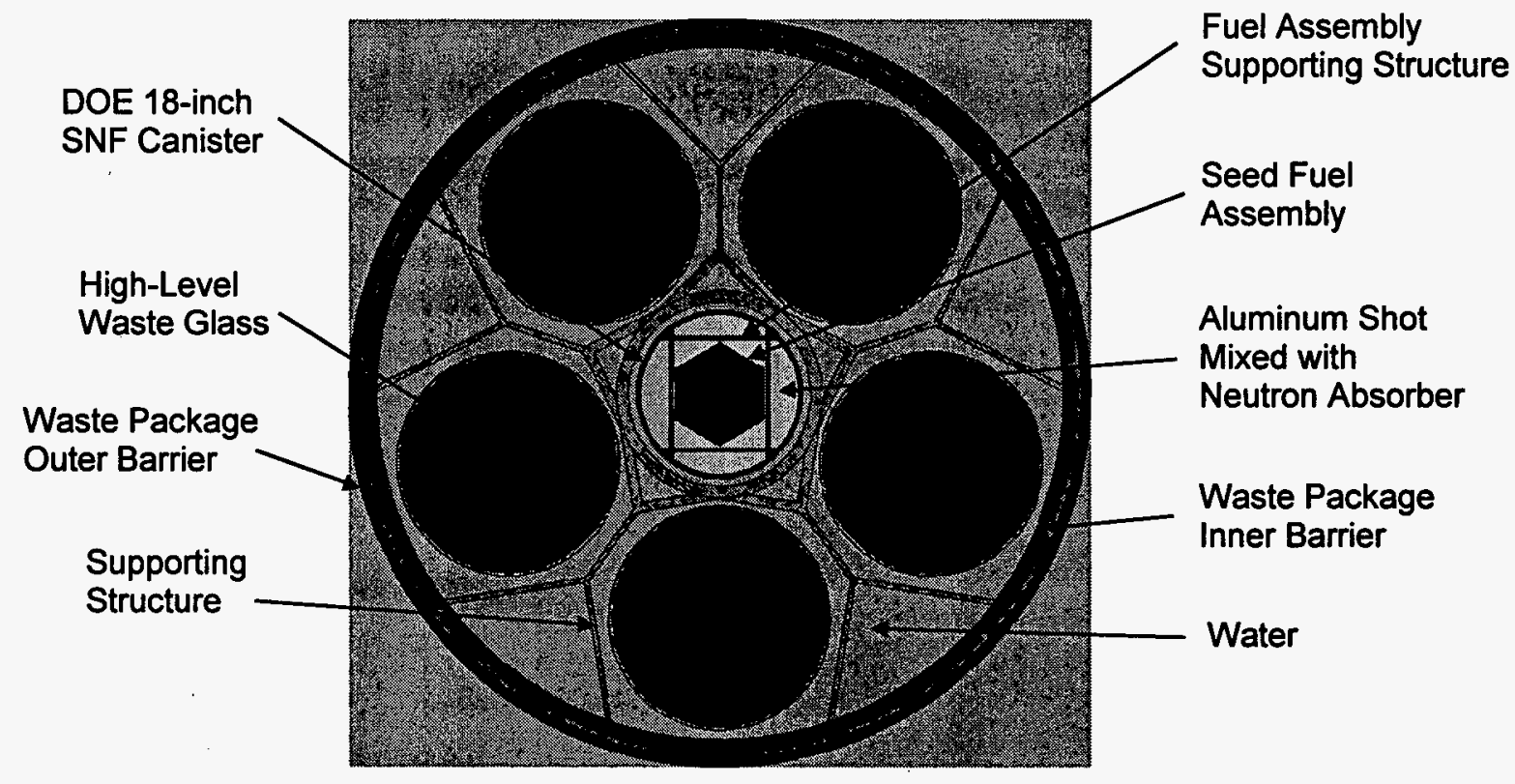

Figure 1. Cross-Sectional View of the Codisposal Waste Package Containing Shippingport LWBR SNF

The Shippingport LWBR seed fuel assembly contains 619 cylindrical fuel rods and is hexagonally shaped ${ }^{3}$. In the form ready for shipping and disposal, the assemblies are between 3302 and 3327.4-mm long and 243.6- $\mathrm{mm}$ across the side planes. There are eight types of Shippingport LWBR seed fuel rods. They feature Zircaloy-4 cladding tubes loaded with cylindrical ceramic pellets of thoria $\left(\mathrm{ThO}_{2}\right)$ or a mixture of thoria and $\mathrm{UO}_{2}$. The uranium used in fabricating the fuel had a very high concentration of U-233 (98.23 wt\%). The initial weight percent fissile concentration in the pellet stack was either $4.34 \%$ or $5.20 \%$, depending on the rod type. The fissile and fertile concentrations vary axially and radially across the seed assembly. The maximum fissile content (U-233 and U-235) of a Shippingport LWBR seed assembly is $16.6 \mathrm{~kg}$ and the maximum linear distribution of the fissile material is $92.5 \mathrm{~g} / \mathrm{cm}$.

The DOE SNF canister accommodates one hexagonal seed assembly. The proposed arrangement (Figure 1) has the fuel assembly placed inside a $295 \times 257 \mathrm{~mm}$ rectangular support. A spacer structure is fitted inside the support to form a $3350-\mathrm{mm}$-long compartment to limit the axial movement of the assembly inside the canister. The space between the assembly and canister is filled with aluminum shot to exclude water that may enter the canister at some time after the waste package and canister have been breached. The filler has a neutron absorber (gadolinium phosphate - $\mathrm{GdPO}_{4}$ ) mixed into it. The $\mathrm{Gd}$ content is $1 \mathrm{wt} \%$ of the $\mathrm{Al}-\mathrm{GdPO}_{4}$ mixture. 


\section{DEGRADATION AND GEOCHEMISTRY ANALYSES}

The degradation analyses follow the general methodology ${ }^{1}$ developed for all waste forms containing fissile material. The analyses evaluate the potential critical configurations from an intact (i.e., intact components, within a breached waste package containing water as a moderator) through a degraded waste package. The intact configuration is the waste package design developed for the time of disposal, and it is used as a starting point for a sequence of events and/or processes of component degradation. Potentially critical configurations of the waste package with Shippingport LWBR SNF are identified for further analysis.

The geochemistry analyses were performed using the EQ3/6 software package ${ }^{4}$ in the flowthrough mode. Water with the composition of J-13 well water ${ }^{5}$ is assumed to drip through an opening at the top of the breach waste package and breached SNF canister, pool inside and eventually overflow, allowing soluble components to be removed through continual dilution.

Twenty-six EQ6 reaction path calculations were done to span the range of possible system behavior and assess the specific and coupled effects of SNF degradation, steel corrosion, HLW glass degradation, and fluid influx rate on $\mathrm{U}, \mathrm{Gd}$ and $\mathrm{Th}$ mobilization. The results show that loss of $\mathrm{Gd}$ was insignificant $(<3.7 \%)$, when it is present in the waste package as $\mathrm{GdPO}_{4}$. Uranium losses from the spent nuclear fuel only, varied from 0.09 to $100 \%$ for the full range of corrosion, degradation, and fluid influx rates considered, and for the assumed failure of the fuel cladding, as well. At a given glass dissolution rate, uranium loss varies inversely with the influx of water. Thorium oxide was very stable for the time range studied (up to 300,000 years), and the loss is very small $(<0.03 \%)$.

\section{INTACT AND DEGRADED COMPONENT CRITICALITY ANALYSIS}

The method used to perform the criticality calculations consisted of using the 4B2 version of the MCNP computer code ${ }^{6}$ to calculate the effective neutron multiplication factor $\left(\mathrm{k}_{\mathrm{eff}}\right)$ of the system for various geometrical configurations. For conservatism, all calculations assumed a fresh fuel composition.

Based on the corrosion rates and the material thickness, the most probable degradation path is identified as follows: the waste package is penetrated and flooded internally; the carbon steel basket inside the waste package degrades; the HLW glass canister shell and glass degrade; the DOE SNF canister is penetrated and flooded; the DOE SNF canister fill material and stainless steel basket degrade; and the fuel assembly and rods stay intact and collect either on the bottom of the degraded DOE SNF canister, or the bottom of the waste package if the canister is degraded. Given a very long period of time, it is postulated that everything will degrade, including cladding and fuel.

For completeness, other less probable and/or overly conservative configurations were investigated. Variations of the internal geometry and compositions were analyzed to cover the entire range of possible parameters. Bounding cases were selected for the configuration classes with a significant number of variations. 
In the first group of configurations analyzed, the Shippingport LWBR seed fuel assembly is considered intact, whereas the other components inside the DOE SNF canister and/or the waste package are considered intact or degraded. Water intrusion into the components is allowed to determine the highest $k_{\text {eff }}$ resulting from optimum moderation. Additionally, the boundary conditions (i.e., geometrical configuration and material compositions around the fuel assembly, DOE SNF canister, and waste package) were varied to determine optimum reflection. Also, the mirror reflection condition is used to demonstrate the effects of neutron leakage on the $\mathrm{k}_{\mathrm{eff}}$ of the system.

The intact configuration (Figure 1) is investigated for varying water densities inside the DOE SNF canister (with or without fill material), the waste package, and the void volume in the fuel pins. The highest $k_{\text {eff }}+2 \sigma$ obtained for the intact configuration is 0.9140 , for the case with water filling all voids inside the fuel pins and the DOE SNF canister (filled with saturated fill material, but no Gd present). The empty spaces in the waste package were treated as voids and the waste package was reflected by full density water.

In the next set of cases within the first group, the intact fuel assembly is surrounded (inside the DOE SNF canister) by degraded basket plates and fill material . The typical configuration is shown in Figure 2. The degradation products, diaspore $(\mathrm{AlOOH})$ and goethite $(\mathrm{FeOOH})$, are conservatively considered to form layers. The complete segregation of the layers is considered extreme with no known mechanism, thus the corresponding configurations are unlikely. However, these configurations are investigated for completeness. The volume fraction of water in layers and the sequence of layers inside the DOE SNF canister are varied. Some values for $\mathrm{k}_{\text {eff }}+2 \sigma$ are above the established interim critical limit of 0.92 . Therefore, $\mathrm{Gd}$ must be added to the filler material in order to keep the $k_{\text {eff }}+2 \sigma$ under 0.92 . The highest $k_{\text {eff }}+2 \sigma, 0.9171$, is obtained for dry goethite and diaspore layers in the configuration shown in Figure 2, and with 1 wt.\% $\mathrm{Gd}(6.3 \mathrm{~kg})$ in the fill material.

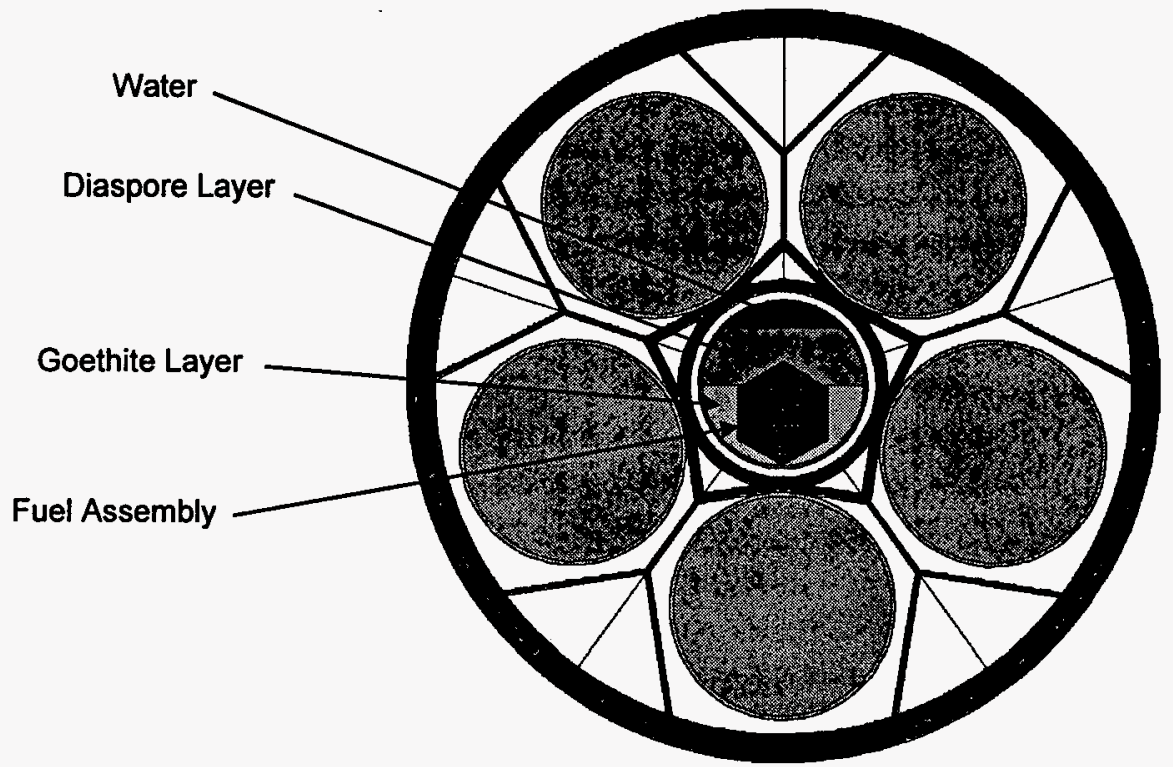

Figure 2. Cross-Sectional View of the Configuration with Fuel Assembly in DOE SNF Canister and Degraded Basket Plates and Fill Material 
The previous two sets of cases are re-investigated with degraded contents of the waste package. The $k_{\text {eff }}+2 \sigma$ results are statistically unchanged for the cases with the DOE SNF canister centered in the waste package, and smaller when the canister is placed at the bottom of the waste package.

In the last set of cases considered for the intact fuel assembly group, the waste package internal components and the DOE SNF canister are completely degraded. It is assumed conservatively that water fills the voids between the fuel pins inside the assembly. Also, segregation of goethite, diaspore, and pre-breach clay layers is assumed. Four parameters are varied: assembly position, mixing fractions, water content in layers, and waste package boundary conditions. For the initial Gd content in the fill material of $1 \mathrm{wt} \%$, the values obtained for $\mathrm{k}_{\mathrm{eff}}+2 \sigma$ are between 0.892 and 0.994 . However, since a fraction of the fill material is initially present inside the assembly, a more realistic set of cases assumes that a mixture of pre-breach clay, goethite, and/or diaspore is present in the assembly flow channels. The results for the configuration shown in Figure 3 indicate that the supplementary condition to keep the $k_{\text {eff }}+2 \sigma$ below the interim critical limit must have diaspore filling at least $10 \mathrm{vol} \%$ of the mixture filling the void volume inside the assembly (i.e., $110 \mathrm{~g}$ of $\mathrm{Gd}$ ).

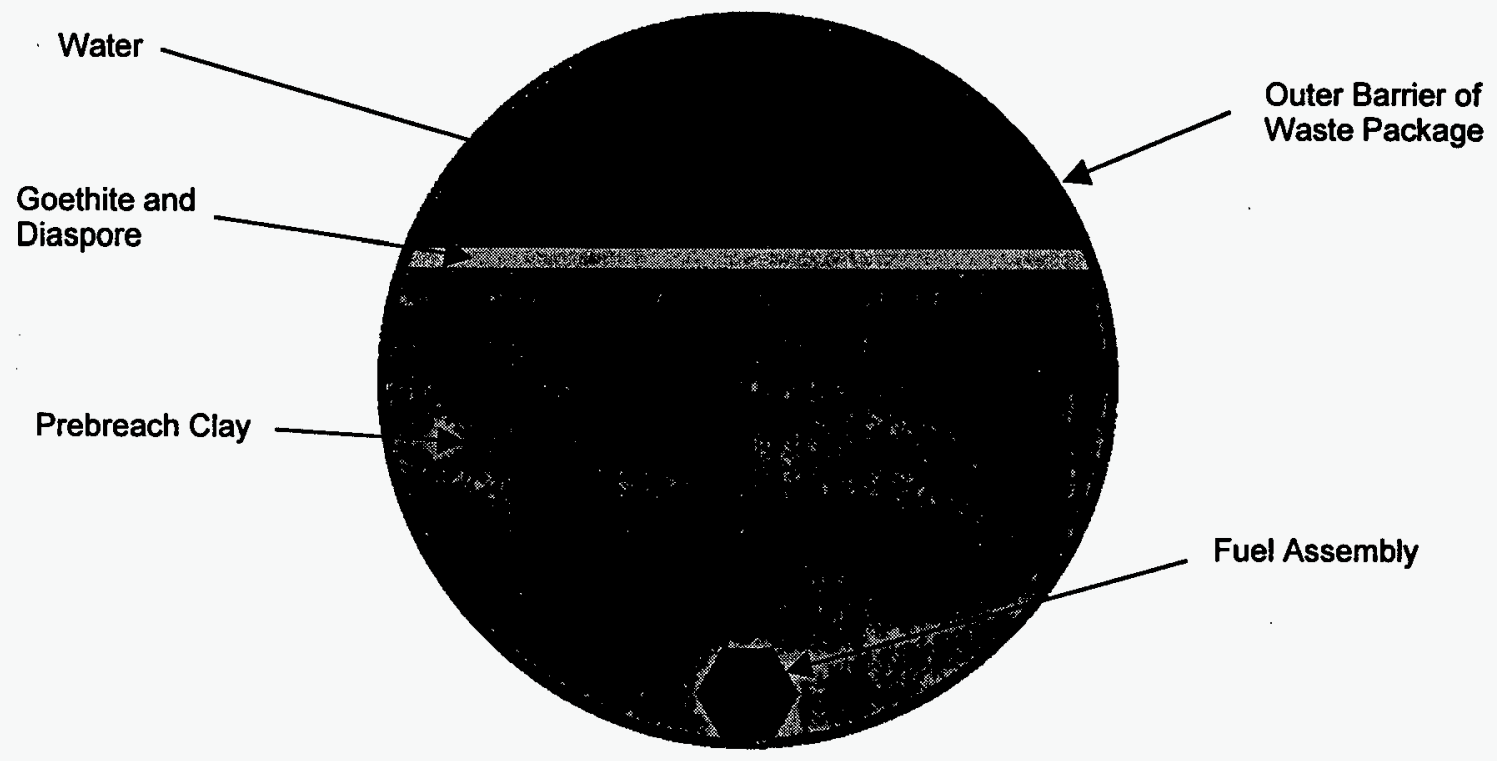

Figure 3. Cross-Sectional View of the Intact Fuel Assembly in the Degraded Waste Package and DOE SNF Canister

The second group of configurations analyzed considered the fuel assembly and the components inside the DOE SNF canister and/or the waste package partially or completely degraded.

The first set of cases analyzed shows that collapsing of the assembly (i.e., reducing the fuel pitch) results in a decrease of $k_{\text {eff. }}$ The fill material contains no Gd.

In the second set, the parameter varied is the axial separation between fuel pellets. The maximum $\mathrm{k}_{\mathrm{eff}}+2 \sigma$ obtained is 0.9040 for a $1.0 \mathrm{~cm}$ axial separation between adjacent pellets and $1 \mathrm{wt} \% \mathrm{Gd}$ initially present in the fill material. 
The third set of cases consists of loose fuel pins inside the DOE SNF canister basket. The parameters varied are the fuel type and pitch. Water fills the void spaces inside the basket assembly, whereas the fill material fills the voids outside the basket assembly. The highest value obtained for $k_{\text {eff }}+2 \sigma$ is 0.9135 , for the original pitch and all pins being considered of type 5 (the most reactive, with $5.202 \mathrm{wt} \% \mathrm{U}-233$ ), and for only $0.1 \mathrm{wt} \% \mathrm{Gd}$ in the fill material.

The fourth set of cases analyzed consists of loose fuel pins settled inside the DOE SNF canister (Figure 4). All pins are considered of type 5. Four parameters are varied: water content in degradation product layers, diaspore content in the bottom layer, pin arrangement (more or less compact) and pitch. In this set of cases and all that follow, $1 \mathrm{wt} \% \mathrm{Gd}$ is considered initially present in the fill material. The results show that for keeping $k_{\text {eff }}+2 \sigma$ below 0.92 , at least 3.5 vol\% of the bottom layer must be diaspore (i.e., $181 \mathrm{~g}$ of $\mathrm{Gd}$ ). An additional set of cases investigates the effect of degraded contents in the waste package, the position of DOE SNF canister inside the waste package, and the water content in the pre-breach clay. The highest value for $k_{\text {eff }}+2 \sigma$ for this set is 0.8994 .

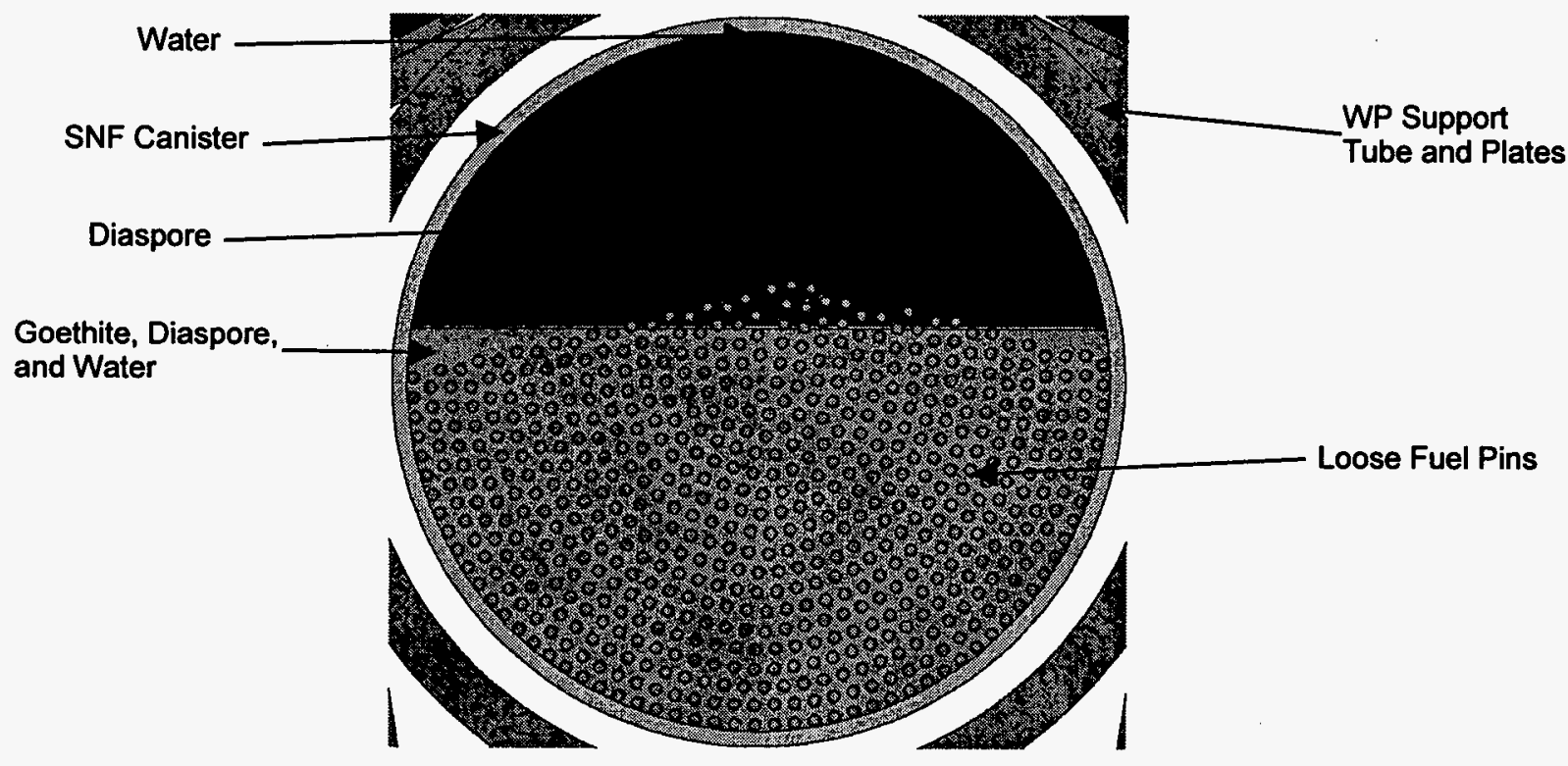

Figure 4. Cross-Sectional View of Loose Fuel Pins in the DOE SNF Canister

The next set of cases consists of loose fuel pins at the bottom of the waste package (Figure 5). Again, four parameters are varied: pitch, water content in the bottom layer, volume fractions of diaspore and goethite in the bottom layer, and boundary conditions. The highest value for $k_{\text {eff }}+$ $2 \sigma$ for this set is 0.8468 . 


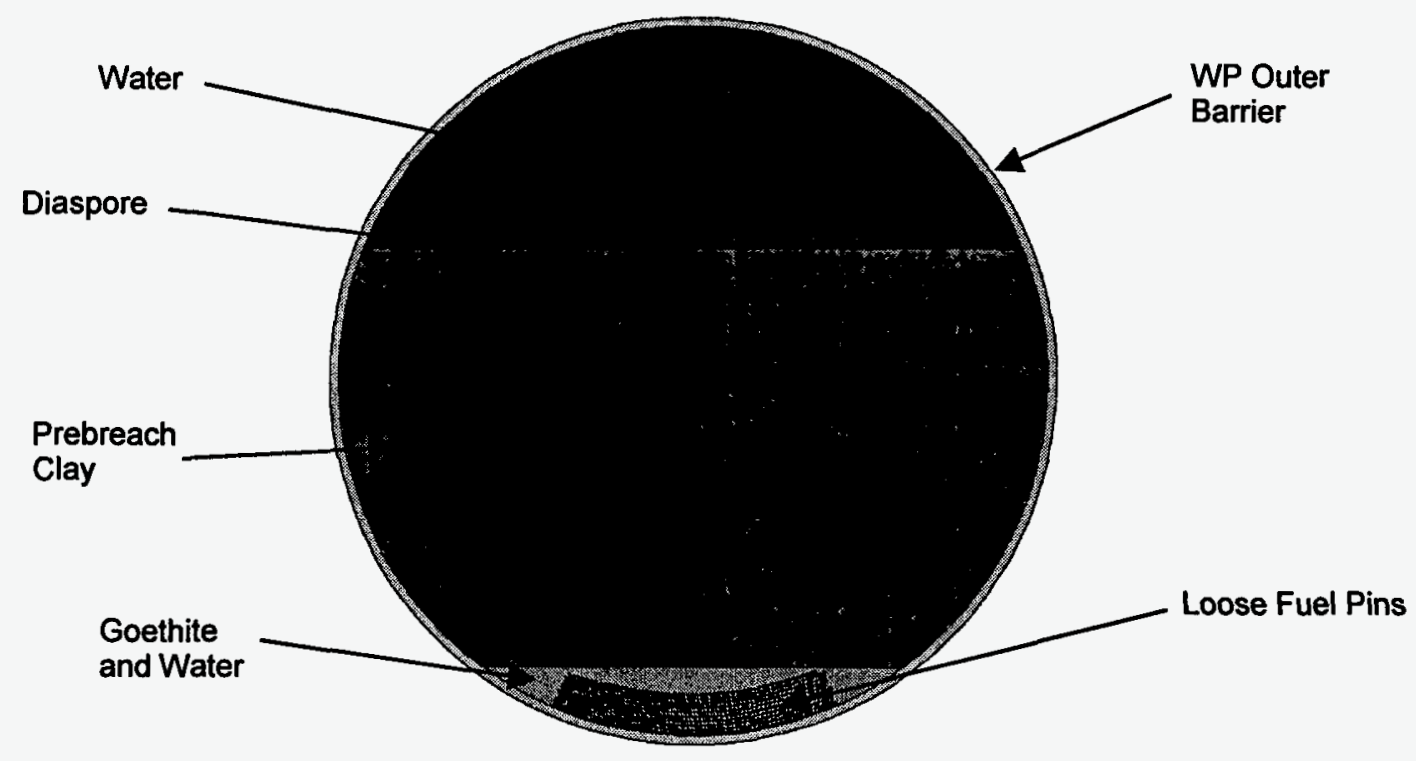

Figure 5. Cross-Sectional View of Loose, Spread Out Fuel Pins in the Waste Package

The next set investigates the fully degraded fuel in intact DOE SNF canister. Three or four layers of degraded fuel, water, and/or degraded components are considered; fuel, water, goethite, and diaspore content in the bottom layer and/or its adjacent layer were varied. The highest value for the $\mathrm{k}_{\mathrm{eff}}+2 \sigma$ obtained is $\mathbf{0 . 8 8 9 4}$.

The last set of cases investigates the fully degraded fuel, DOE SNF canister and waste package contents (Figure 6). The axial loading of goethite, diaspore and degraded fuel is preserved in all cases and the thoria is neglected for most cases. Water fills any vacant spaces not occupied by degradation products in the WP. The highest value for the $k_{\text {eff }}+2 \sigma$ obtained is 0.8941 .

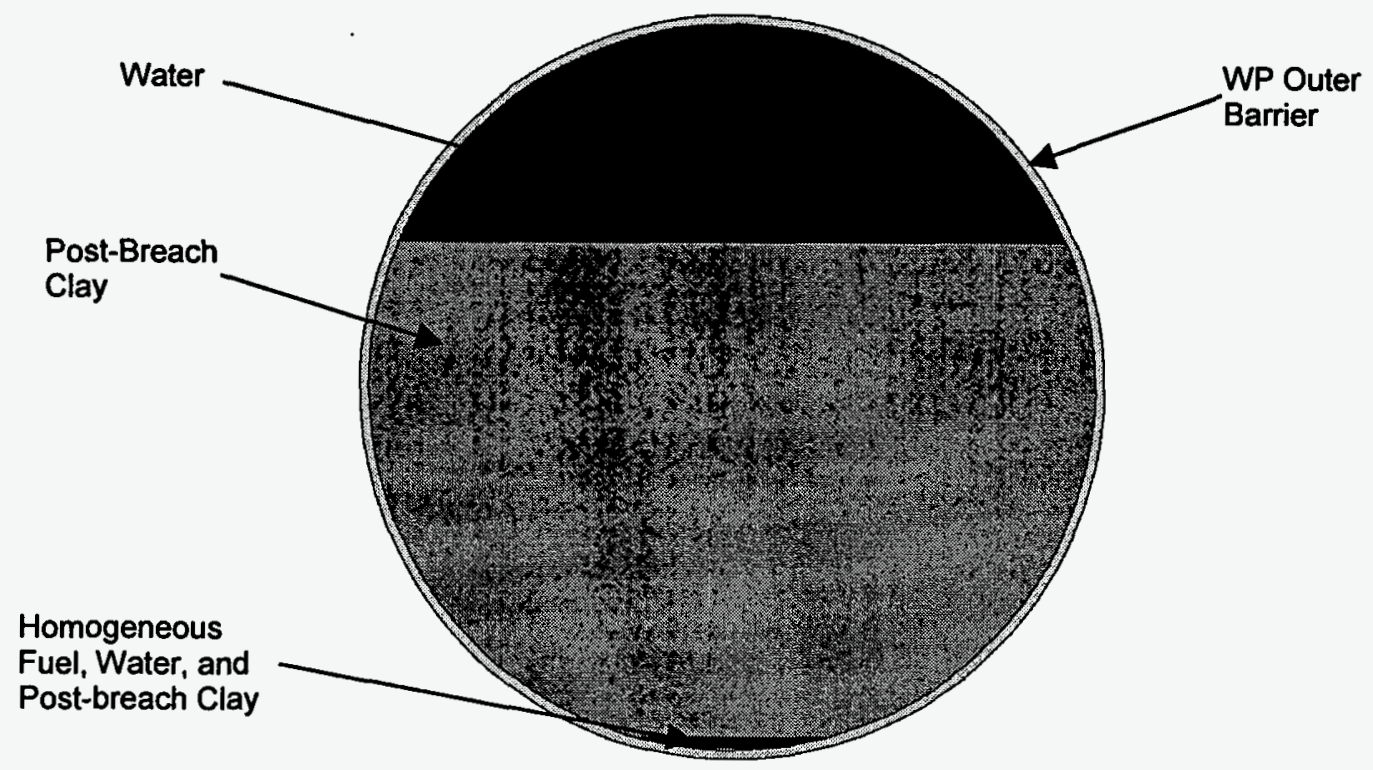

Figure 6. Cross-Sectional View of the Fully Degraded Fuel in the Waste Package 
The effect of U-233 decay is not considered in the criticality calculations, because of the uncertain time range when a specific configuration occurs. However, given the long time periods considered in the disposal criticality calculations (up to 300,000 years), the radioactive decay of U-233, which has a half-life of 159,200 years $^{7}$, significantly affects the U-233 inventory. This effect has been investigated for a few of the cases with the highest $k_{\text {eff }}$ values. For example, after 50,000 years, the $k_{\text {eff }}$ is at least $5 \%$ smaller than for the cases with no U-233 decay considered.

\section{CONCLUSIONS}

The criticality calculations for the internal configurations, intact through degraded, of the codisposal waste package containing Shippingport LWBR spent nuclear fuel were performed using the MCNP code, Version 4B2. The analysis covered the potential critical configurations. The geometry and composition parameters of the system were varied in the calculations to find the maximum $k_{\text {eff }}$ for the configurations investigated. Additional cases were evaluated to determine the amount of neutron absorber $(\mathrm{Gd})$ required in the DOE SNF canister filler material to keep the $\mathrm{k}_{\mathrm{eff}}+2 \sigma$ under the established interim critical limit of 0.92 .

Under the conservative conditions investigated and for the physically possible configurations, the codisposal waste package containing Shippingport $L W B R$ SNF has a $k_{\text {eff }}+2 \sigma$ value less than 0.92 if $1 \mathrm{wt} \% \mathrm{Gd}$ is initially present in the $\mathrm{Al}-\mathrm{GdPO}_{4}$ mixture, and at least $181 \mathrm{~g}$ of Gd is homogeneously distributed in the space inside the fuel assembly or the clay layer containing the degraded fuel. The total fissile loading limit for the DOE SNF canister is $16.6 \mathrm{~kg}$ of U-233 and $\mathrm{U}-235$, and the linear fissile material loading limit is $92.5 \mathrm{~g} / \mathrm{cm}$.

\section{ACKNOWLEDGEMENTS}

This work was performed by the CRWMS M\&O and was sponsored by NSNFP under DOE-EM.

\section{REFERENCES}

1. Disposal Criticality Analysis Methodology Topical Report, YMP/TR-004Q, U.S. Department of Energy, Office of Civilian Radioactive Waste Management, Las Vegas, Nevada, November 1998.

2. Shippingport LWBR (Th/U Oxide) Fuel Characteristics for Disposal Criticality Analysis. DOE/SNF/REP-051 Revision 0. U.S. Department of Energy, Office of Environmental Management, Idaho National Engineering and Environmental Laboratory, Idaho Falls, Idaho, September 1999.

3. Generic Degradation Scenario and Configuration Analysis for DOE Codisposal Waste Package, BBA000000-01717-0200-00071 REV00, CRWMS M\&O, Las Vegas, Nevada, November 1999. 
4. EQ3/6, a Software Package for Geochemical Modeling of Aqueous Systems: Package Overview and Installation Guide, UCRL-MA-110662 PT I, Lawrence Livermore Laboratory, Livermore, California, September 1992.

5. Evaluation of Codisposal Viability for Th/U Oxide (Shippingport LWBR) DOE-Owned Fuel, TDR-EDC-NU-000005 REV 00, CRWMS M\&O, Las Vegas, Nevada, September 2000.

6. MCNP-A General Monte Carlo N-Particle Transport Code, Version 4-UC 705 and UC 700, LA-12625-M, Version 4B, Los Alamos National Laboratory, Los Alamos, March 1997.

7. Nuclides and Isotopes Fifteenth Edition: Chart of the Nuclides, J.R. Parrington et al., General Electric Company, 1996. 